\title{
Apoptotic effect of sodium acetate on a human gastric adenocarcinoma epithelial cell line
}

\author{
Y. Xia ${ }^{1 *}$, X.L. Zhang ${ }^{2 *}$, F. Jin ${ }^{3 *}$, Q.X. Wang ${ }^{1}$, R. Xiao ${ }^{1}$, Z.H. Hao ${ }^{4}$, \\ Q.D. Gui ${ }^{5}$ and J. Sun ${ }^{1}$ \\ ${ }^{1}$ Inner Mongolia Medical University, Hohhot, China \\ ${ }^{2}$ Capital Medical University, Beijing, China \\ ${ }^{3}$ Inner Mongolia Vocational College of Chemical Engineering, Hohhot, China \\ ${ }^{4}$ Inner Mongolia People's Hospital, Hohhot, China \\ ${ }^{5}$ International Mongolia Hospital of Inner Mongolia, China \\ *These authors contributed equally to this study. \\ Corresponding author: J. Sun \\ E-mail: 2573479397@qq.com
}

Genet. Mol. Res. 15 (4): gmr. 15048375

Received January 4, 2016

Accepted August 10, 2016

Published October 5, 2016

DOI http://dx.doi.org/10.4238/gmr.15048375

Copyright (C) 2016 The Authors. This is an open-access article distributed under the terms of the Creative Commons Attribution ShareAlike (CC BY-SA) 4.0 License.

\begin{abstract}
The objective of this study was to investigate the effect of sodium acetate on the viability of the human gastric adenocarcinoma (AGS) epithelial cell line. AGS cells were exposed to a range of concentrations of sodium acetate for different periods of time, and the sodium acetate-induced cytotoxic effects, including cell viability, DNA fragmentation, apoptotic gene expression, and caspase activity, were assessed. The changes in these phenotypes were quantified by performing a lactate dehydrogenase cell viability assay, annexin $\mathrm{V}$ staining, terminal deoxynucleotidyl transferase-mediated dUTP nickend labeling (TUNEL), and several caspase activity assays. In vitro studies demonstrated that the cytotoxicity of sodium acetate on the AGS cell line were dose- and time-dependent manners. No differences
\end{abstract}


were found between the negative control and sodium acetate-treated cells stained with annexin V and subjected to the TUNEL assay. However, caspase-3 activity was increased in AGS cells exposed to sodium acetate. Overall, it was concluded that sodium acetate exerted an apoptotic effect in AGS cells via a caspase-dependent apoptotic pathway.

Key words: AGS cells; Apoptosis; Cytotoxicity; Sodium acetate.

\section{INTRODUCTION}

Sodium acetate, the sodium salt of acetic acid, is a short-chain fatty acid that is used in the food industry as a flavoring agent and to control $\mathrm{pH}$ (US Government Printing Office, 2011). Sodium acetate is produced naturally via host metabolic pathways, particularly in the liver (Høverstad and Midtvedt, 1986). However, humans fulfill a majority of their sodium acetate needs via dietary fiber, resistant starches, and complex carbohydrates metabolized by anaerobic microorganisms in the human intestine (Cook and Sellin, 1998). The most efficient pathway used by bacteria to produce acetate is the oxygen-sensitive Wood-Ljungdahl pathway (Fast and Papoutsakis, 2012). The cytotoxic effects of sodium acetate on human cells have been extensively studied. For example, acetate inhibits the histone deacetylase (HDAC) activity via tissue- or cellspecific mechanisms (Waldecker et al., 2008; Soliman and Rosenberger, 2011). Rodent neutrophils exposed to acetate undergo global inhibition of HDAC activity (Vinolo et al., 2011). Treatment with $1 \mathrm{mM}$ acetate significantly reduces the HDAC activity and increases global histone acetylation in human macrophages, corresponding to a decrease in inflammatory cytokine [interleukin (IL)-6, IL-8, and tumor necrosis factor (TNF)-a] production (Kendrick et al., 2010). Conversely, human gastric adenocarcinoma (AGS) cells treated with sodium acetate for $24 \mathrm{~h}$ showed increased mRNA and protein levels of IL-1 $\beta$, IL-8, and TNF- $\alpha$. Previous studies have suggested that food containing high concentrations of sodium acetate could have cytotoxic effects (Sun et al., 2005). The contradictions between these results and other published results may be attributed to the differences in cell type and dose of sodium acetate. Acetate mediates its cytotoxicity through various molecular mechanisms, one of which is via the G-protein-coupled receptor (GPCR) signaling. Acetate is a ligand for the GPCRs GPR41 and GPR43 in adipose tissue; these receptors are significantly expressed in immune cells and endothelial cells of other tissues (Brown et al., 2003). Acetate promotes the release of reactive oxygen species in mouse neutrophils by activating GPR43 (Maslowski et al., 2009). Acetate inhibits human neutrophil migration toward C5a or formyl-methionyl-leucyl-phenylalanine (fMLP) in a GPR43-dependent manner under inflammatory conditions (Vinolo et al., 2011). Acetate also induces partial lysosomal membrane permeabilization and the subsequent release of cathepsin D to the cytosol of apoptotic colorectal cancer cells (Marques et al., 2013).

Oncogenesis is caused by a combination of genetic and environmental factors, including exposure to radiation and chemical carcinogens, and the diet. In fact, the role of diet in cancer development, especially cancers of the digestive tract, is strongly supported by epidemiological studies (Willett, 2000). Because of the major impact of eating habits on the prevalence of gastric cancers, significant efforts have been made to design an

Genetics and Molecular Research 15 (4): gmr.15048375 
optimal diet and/or to create food supplements that specifically lower the risk of cancer. Thus far, the cytotoxic effects of sodium acetate on colonic epithelial cells have been investigated extensively. However, once introduced to the human body via the oral route, organs other than the colon, such as the stomach, may be exposed to sodium acetate. Therefore, the biological toxicity of sodium acetate may not be restricted to the colon, and may extend to other parts of the human body.

The aim of this study was to demonstrate the killing capacity of sodium acetate against AGS cells. Furthermore, we have investigated the mechanism by which sodium acetate induces apoptosis of AGS cells.

\section{MATERIAL AND METHODS}

\section{Materials}

The AGS cell line (Dainippon Pharmaceutical Co. Ltd., Osaka, Japan) was originally cultured from stomach adenocarcinoma cells obtained prior to any anti-cancer treatment (Barranco et al., 1983). Sodium acetate was purchased from Sigma-Aldrich (St. Louis, MO, USA). The Quick Cell Proliferation Assay and Annexin V-PE (phycoerythrin) Apoptosis Detection kits were purchased from Medical \& Biological Laboratories (Aichi, Japan). The lactate dehydrogenase (LDH)-cytotoxicity assay kit was purchased from Biovision (Milpitas, CA, USA) and the ApoAlert DNA Fragmentation Assay kit was purchased from BD Biosciences (Franklin Lakes, CA, USA). Caspase-3, -6, -8, and -9 colorimetric protease assays were purchased from Beyotime (Shanghai, China). The DNA Fragmentation Assay kit was purchased from BDBiosciences. Ham's F12 medium and fetal bovine serum were purchased from Gibco (Thermo Fisher Scientific, Waltham, MA, USA).

\section{Cell culture and treatments}

The cells were cultured in Ham's F12 medium supplemented with $10 \%$ fetal bovine serum, L-glutamine, antibiotics (100 U/mL penicillin), and antimycotics $(100 \mathrm{mg} / \mathrm{mL}$ streptomycin) in a humidified incubator at $37^{\circ} \mathrm{C}$ and $5 \% \mathrm{CO}_{2}$. Cells in the mid-log phase of growth were used for all experiments.

Sodium acetate was dissolved in sterile double distilled water to a stock concentration, and diluted to the indicated concentrations in Ham's F12 medium. AGS cells were seeded to a sub-confluent density of $5 \times 10^{4}$ cells/well on 24-well plates (Corning, Corning, NY, USA), and the culture plates were incubated in a humidified incubator at $37^{\circ} \mathrm{C}, 5 \% \mathrm{CO}_{2}$, and ambient air, in the presence or absence of sodium acetate $(0-50 \mathrm{mM})$.

\section{Cell proliferation assays}

The cells were seeded on 96-well culture plates (BD Biosciences) at a concentration of $3 \times 10^{3}$ cells/well. The culture plates were incubated at $37^{\circ} \mathrm{C}$ in a $5 \% \mathrm{CO}_{2}$ incubator in the presence or absence of sodium acetate $(0-50 \mathrm{mM})$. Cell proliferation was measured at 1, 4, 8, and $24 \mathrm{~h}$ using the Quick Cell Proliferation Assay kit according to the manufacturer protocols.

Genetics and Molecular Research 15 (4): gmr.15048375 


\section{$\mathrm{LDH}$ release assay}

Cell cytotoxicity was measured based on the release of LDH from cells. Briefly, LDH levels in the supernatant of cells pre-treated with $3.13,6.25,12.5,25$, or $50 \mathrm{mM}$ sodium acetate for 8 or $24 \mathrm{~h}$ were quantified using the LDH-cytotoxicity assay kit. LDH oxidizes lactate to pyruvate, which forms a red formazan product with iodotetrazolium chloride. The amount of formazan present in the supernatant is directly correlated to the number of lysed cells. The formazan dye was quantified by spectrophotometry at a wavelength of $500 \mathrm{~nm}$. Triton X-100 (1\%)-treated cells were used as the positive control. The cytotoxicity induced by each dose of acetate was expressed as a percentage of LDH released by treated cells to that released by cells treated with $1 \%$ Triton X-100.

\section{Annexin V- PE measurement of apoptosis}

AGS cells were cultured to sub-confluency and exposed to sodium acetate for up to 24 h. The apoptotic cells were stained with Annexin V-PE according to the manufacturer protocols. Briefly, $1 \times 10^{5}$ cells were washed twice in phosphate-buffered saline and re-suspended in 500 $\mu \mathrm{L}$ Annexin buffer. The cells were then exposed to a labeling solution containing PE-conjugated Annexin $\mathrm{V}$ antibody for $5 \mathrm{~min}$ and subsequently analyzed by fluorescent microscopy.

\section{DNA fragmentation detection in vitro}

DNA fragmentation in AGS cells was measured by labeling terminal deoxynucleotidyl transferase (TdT)-mediated dUTP nicks using the ApoAlert DNA Fragmentation Assay kit. Camptothecin-treated cells were used as the positive control. The number of terminal deoxynucleotidyl transferase-mediated dUTP nick-end labeling (TUNEL)-positive apoptotic cells was quantified using a fluorescentmicroscope (Nikon, Tokyo, Japan) equipped with fluorescein isothiocyanate filters, in accordance with the manufacturer recommendations. Data are reported as the percentage of TUNEL-positive cells among the total number of cells in six fields. Each experiment was performed in triplicate.

\section{Caspase activity assay}

Caspase-3, -6, -8, and -9 activity levels were measured using the appropriate ApoTarget ${ }^{\mathrm{TM}}$ Caspase colorimetric kitin accordance with the manufacturer protocols. Briefly, cells treated with $0,6.25,12.5,25$, or $50 \mathrm{mM}$ sodium acetate for 1,4 , or $24 \mathrm{~h}$ were lysed; 10 $\mu \mathrm{L}$ lysate protein was incubated with $80 \mu \mathrm{L}$ reaction buffer containing $10 \mu \mathrm{L}$ of the relevant substrate on 96 -well plates at $37^{\circ} \mathrm{C}$ for $4 \mathrm{~h}$ or overnight; the absorbance of the mixture was then measured at a wavelength of $405 \mathrm{~nm}$.

\section{Statistical analysis}

Data are reported as means \pm standard deviation of three independent experiments. Statistical analysis was performed using unpaired $t$-tests. $\mathrm{P}$ values $<0.05$ were considered to be statistically significant.

Genetics and Molecular Research 15 (4): gmr.15048375 


\section{RESULTS}

\section{Effect of sodium acetate on AGS cell viability}

AGS cell cytotoxicity was assessed by determining the amount of LDH released after incubating the cells with increasing concentrations of sodium acetate. As shown in Figure 1, AGS cells cultured in the presence of $6.25 \mathrm{mM}$ sodium acetate for $24 \mathrm{~h}$ showed an increase in LDH concentration compared to the negative control cells; however, the LDH release was less than $3 \%$. LDH release increased to $2.1,3.8$, and $7.0 \%$ after the cells were treated with 12.5 , 25 , and $50 \mathrm{mM}$ sodium acetate for $24 \mathrm{~h}$ (Figure 1). That is, AGS cells incubated for only 1 or $4 \mathrm{~h}$ with 6.25-50.0 mM sodium acetate showed no LDH release, whereas a longer incubation induced a dose-dependent increase in LDH release (Figure 1), indicating the time dependence of sodium acetate-dependent cytotoxicity. Although incubation with $50 \mathrm{mM}$ sodium acetate for $24 \mathrm{~h}$ led to a decrease in cell viability compared to that seen in control cells treated with $1 \%$ Triton X-100, a maximum reduction of $7.0 \%$ was observed.

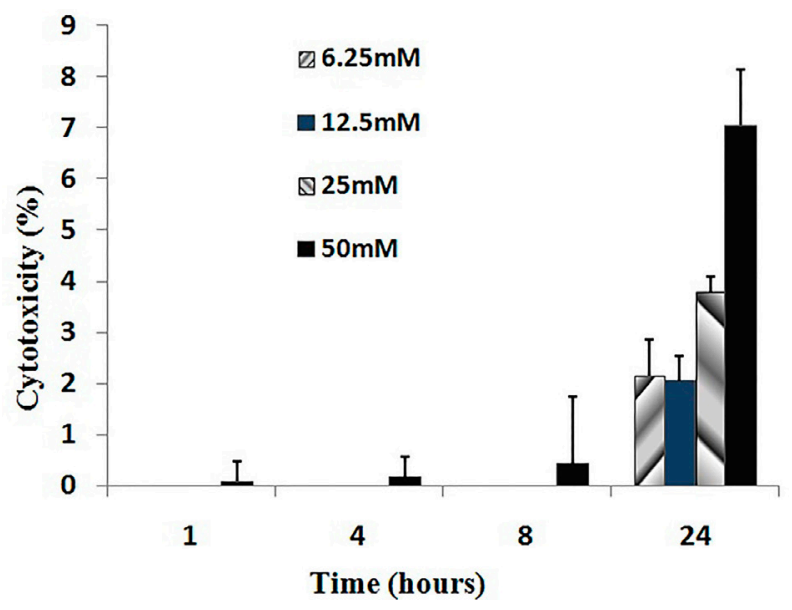

Figure 1. AGS cell viability following exposure to varying concentrations of sodium acetate, measured by the release of lactate dehydrogenase. Results shown are representative of three independent experiments.

\section{Effect of sodium acetate on caspase activity in AGS cells}

Apoptosis proceeds via a series of biochemical events that are distinct from those that occur during necrosis. The apoptotic molecular pathway involves the activation of cysteine proteases, which include both initiators and executors of cell death. This activation does not occur during necrosis. Caspase-3, an executor of programmed cell death, was activated following exposure of cells to sodium acetate for $6 \mathrm{~h}$ (Figure 2). Caspase-3 was significantly activated in the presence of $50 \mathrm{mM}$ sodium acetate. Although caspase- 8 is an initiator of cell death, caspase- 8 activation was weak compared to the control after $6 \mathrm{~h}$ (Figure 2c). Alternately, we observed a $11 \%$ increase in caspase- 9 activity after incubating the cells with $50 \mathrm{mM}$ sodium acetate for $6 \mathrm{~h}$ (Figure 2d).

Genetics and Molecular Research 15 (4): gmr.15048375 
In contrast, caspase- 3 activity increased after exposure to $50 \mathrm{mM}$ sodium acetate for 1,3 , and $4 \mathrm{~h}$ (Figure 2a). The activity of caspase- 6 also significantly increased after 1 and $4 \mathrm{~h}$ in the presence of $50 \mathrm{mM}$ sodium acetate (Figure 2b).
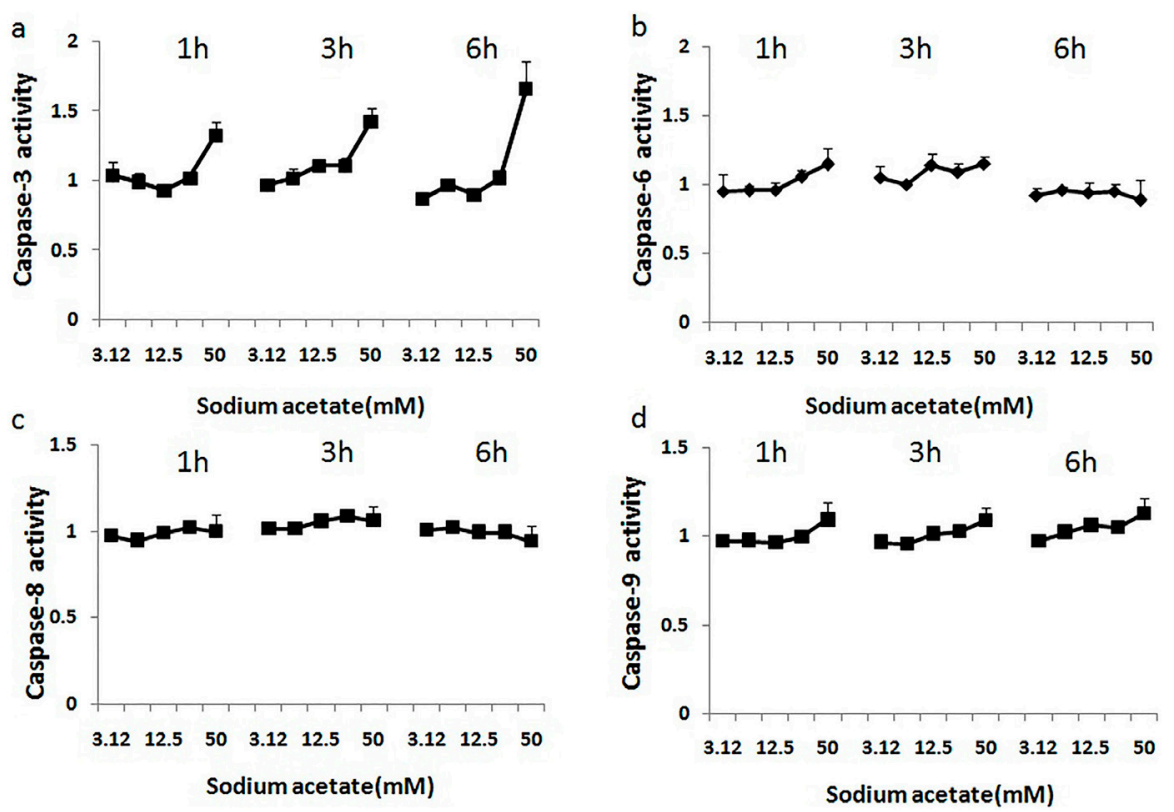

Figure 2. Effects on caspase-3 (a), caspase-6 (b), caspase-8 (c), and caspase-9 (d) activity in AGS cells following incubation with varying concentrations of sodium acetate for different time periods. Results shown are representative of three independent experiments.

\section{Effect of sodium acetate on apoptosis}

AGS cells were stained with Annexin $\mathrm{V}$ after treating with varying concentrations of sodium acetate for $8 \mathrm{~h}$. We observed no differences between the treated and untreated cells at all concentrations, suggesting that none of the cells were apoptotic (data not shown). The percentage of cells with fragmented DNA (TUNEL-positive) was calculated using fluorescence microscopy. TUNEL-positive cells displayed intense green fluorescence, while TUNEL-negative cells displayed blue fluorescence indicative of nuclear staining. No apoptotic cells were detected in the control group.

Cells exposed to $3.1 \mathrm{mM}$ sodium acetate displayed little to no DNA fragmentation at any of the time points examined (Figure 3). However, a higher concentration of sodium acetate $(50 \mathrm{mM})$ induced DNA fragmentation at all of the time points. Intermediate concentrations (6.2-12.5 mM) of sodium acetate induced DNA fragmentation in a time- and concentrationdependent manner. 


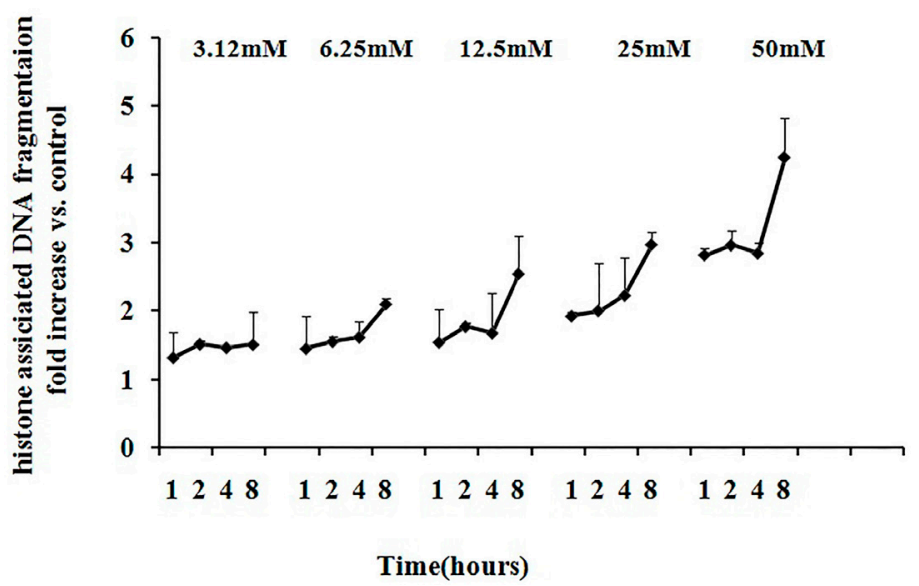

Figure 3. Histone-associated DNA fragmentation in AGS cells treated with varying concentrations of sodium acetate for different time periods. Results shown are representative of three independent experiments.

\section{DISCUSSION}

Acetate, one of the most important short-chain fatty acids, has become the subject of investigation in recent years. Sodium acetate imparts a salty and sour flavor to food, and is commonly used as a seasoning. The cytotoxic properties of sodium acetate have also been extensively investigated. Sodium acetate has been reported to induce differentiation as well as apoptosis, and arrest growth in colorectal cancer cell lines. The antitumor effect of acetate stems from its ability to induce cell death in colon cancer cells via mitochondria-mediated apoptosis or necrosis (Marques et al., 2013). Our previous study has also shown that $12.5 \mathrm{mM}$ sodium acetate stimulates AGS cell viability and proliferation in a dose-dependent manner. However, the addition of sodium acetate at quantities higher than $12.5 \mathrm{mM}$ inhibits cell growth in a dose-dependent manner. Furthermore, cells incubated with sodium acetate for 24 $\mathrm{h}$ exhibited an increase in IL- $1 \mathrm{~b}$, IL-8, and TNF- $\alpha$ expression; this effect of sodium acetate was also verified in mice. Our data suggested that food containing high concentrations of sodium acetate induces cytotoxicity (Sun et al., 2005). Acetate has also been shown to actively suppress NF-KB activity in Colo320DM cells (Tedelind et al., 2007). Under inflammatory conditions, the addition of acetate has been shown to inhibit human neutrophil migration toward C5a or fMLP in a GPR43-dependent manner (Vinolo et al., 2011). Phenylacetamide, a human GPR43 agonist, mimics these effects. In addition to suppressing the neutrophil function, acetate inhibits IL-2 production and lymphocyte proliferation in vitro (Cavaglieri et al., 2003).

Apoptosis is a form of programmed cell death that can occur in tumor cells. The cellular structure is destroyed during apoptosis as an end result of caspase-mediated events. Apoptosis can occur via two pathways, the extrinsic and intrinsic pathways. The extrinsic pathway is triggered by the Fas receptor, which depends on both FasL and Fas. In the intrinsic pathway, the sensing of a stimulus that causes mitochondrial outer membrane permeabilization and cytochrome-c release leads to apoptosis (Eisenberg-Lerner et al., 2009; Rikiishi, 2012).

In this study, the sodium acetate-induced apoptosis was studied in AGS cells in vitro. Incubation of AGS cells with 25 and $50 \mathrm{mM}$ sodium acetate for $24 \mathrm{~h}$ was shown to reduce the cell viability. Similar results were obtained using the Annexin V staining assay. These 
observations were in agreement with the results of a previous study, wherein exposure to 25 or $50 \mathrm{mM}$ sodium acetate for 12 or $24 \mathrm{~h}$ affected the viability of AGS cells (Sun et al., 2005). Less than $2 \%$ of the cells exposed to $3.12 \mathrm{mM}$ sodium acetate underwent DNA fragmentation at all time points (Figure 3). The percentage of cells exhibiting DNA fragmentation increased to $4.2 \%$ after incubating the cells with a higher concentration of sodium acetate $(50 \mathrm{mM})$ for $8 \mathrm{~h}$. Apoptosis plays an important role in maintaining cell homeostasis. Therefore, an analysis of the expression of genes driving the intrinsic and extrinsic apoptotic pathways could help elucidate the mechanisms involved in sodium acetate-induced apoptosis in AGS cells. In view of the findings reported by our, and other, groups, the apoptotic gene expression was investigated in this study, in order to characterize the sodium acetate-induced apoptosis in AGS cells.

The FasR/FasL system is a major apoptotic pathway that plays an important role in cell colony maintenance, elimination of malignant cells, and apoptosis regulation. Most cancer cells express both FasR and FasL. The interaction between these molecules on the tumor cell surface results in the formation of a complex that initiates apoptotic signaling, leading to the activation of caspases, which in turn interacts with cytoplasmic signaling proteins that induce apoptosis (Dai et al., 2009). In this study, we observed an increase in the FasL and FasR mRNA expression after treatment with 12.5-50 mM sodium acetate in a dose-dependent manner. A subset of caspases is activated when apoptosis is triggered by Fas. Caspase- 8 is the first step in the cascade of apoptotic events induced by Fas. Caspase-8, activated when it is cleaved, then activates other downstream caspases, thereby committing the cell to apoptosis (Qi et al., 2012).

The response of this pathway to sodium acetate was investigated by analyzing the caspase- $3,-6,-8$, and -9 activities. Caspases are cysteine proteases that play a key role in the execution of apoptosis (Creagh, 2014). Caspase- 8 and -9 are self-activating initiators of apoptosis, whereas caspase- 3 and -6 are believed to be executors of apoptosis through the decomposition of cellular proteins. Caspase-3 is present in many cells and induces apoptosis via different mechanisms (Park et al., 2005). In this study, caspase- 3 was activated by treating the cells with sodium acetate for $6 \mathrm{~h}$; caspase- 3 was significantly activated in the presence of $50 \mathrm{mM}$ sodium acetate. It has been established that acetate induces mitochondrial apoptotic death, as well as MP in RCs. Caspase-3 plays a crucial role in the cell death process (Jan et al., 2002; Marques et al., 2013; Oliveira et al., 2015). In this study, caspase-8 activity changed weakly after $6 \mathrm{~h}$, while caspase- 9 activity increased by $11 \%$ after $6 \mathrm{~h}$ in the presence of 50 $\mathrm{mM}$ sodium acetate. Therefore, activated caspase- 9 may cleave and activate the downstream caspases, including caspase-3, which in turn cleave the cytoskeletal and nuclear proteins, leading to apoptosis. In summary, we deduced that sodium acetate has an apoptotic effect on AGS cells via a caspase-dependent apoptotic pathway. Although the risk related to the use of chemical additives can be evaluated by in vitro toxicology experiments, these results can be subject to certain limitations. Therefore, our results should be further verified in vivo.

\section{Conflicts of interest}

The authors declare no conflict of interest.

\section{ACKNOWLEDGMENTS}

Research supported by grants provided by the National Natural Science Foundation of China (grant \#81473017 and \#31460249).

Genetics and Molecular Research 15 (4): gmr.15048375 


\section{REFERENCES}

Barranco SC, Townsend CM, Jr., Casartelli C, Macik BG, et al. (1983). Establishment and characterization of an in vitro model system for human adenocarcinoma of the stomach. Cancer Res. 43: 1703-1709.

Brown AJ, Goldsworthy SM, Barnes AA, Eilert MM, et al. (2003). The Orphan G protein-coupled receptors GPR41 and GPR43 are activated by propionate and other short chain carboxylic acids. J. Biol. Chem. 278: 11312-11319. http:// dx.doi.org/10.1074/jbc.M211609200

Cavaglieri CR, Nishiyama A, Fernandes LC, Curi R, et al. (2003). Differential effects of short-chain fatty acids on proliferation and production of pro- and anti-inflammatory cytokines by cultured lymphocytes. Life Sci. 73: 16831690. http://dx.doi.org/10.1016/S0024-3205(03)00490-9

Cook SI and Sellin JH (1998). Review article: short chain fatty acids in health and disease. Aliment. Pharmacol. Ther. 12: 499-507.http://dx.doi.org/10.1046/j.1365-2036.1998.00337.x

Creagh EM (2014). Caspase crosstalk: integration of apoptotic and innate immune signalling pathways. Trends Immunol. 35: 631-640.http://dx.doi.org/10.1016/j.it.2014.10.004

Dai ZJ, Gao J, Ji ZZ, Wang XJ, et al. (2009). Matrine induces apoptosis in gastric carcinoma cells via alteration of Fas/ FasL and activation of caspase-3. J. Ethnopharmacol. 123: 91-96.http://dx.doi.org/10.1016/j.jep.2009.02.022

Eisenberg-Lerner A, Bialik S, Simon HU and Kimchi A (2009). Life and death partners: apoptosis, autophagy and the cross-talk between them. Cell Death Differ. 16: 966-975.http://dx.doi.org/10.1038/cdd.2009.33

Fast AG and Papoutsakis ET (2012). Stoichiometric and energetic analyses of non-photosynthetic $\mathrm{CO}_{2}$-fixation pathways to support synthetic biology strategies for production of fuels and chemicals. Curr. Opin. Chem. Eng. 1: 380-395. http://dx.doi.org/10.1016/j.coche.2012.07.005

Høverstad T and Midtvedt T (1986). Short-chain fatty acids in germfree mice and rats. J. Nutr. 116: 1772-1776.

Jan G, Belzacq AS, Haouzi D, Rouault A, et al. (2002). Propionibacteria induce apoptosis of colorectal carcinoma cells via short-chain fatty acids acting on mitochondria. Cell Death Differ. 9: 179-188. http://dx.doi.org/10.1038/ sj.cdd. 4400935

Kendrick SFW, O’Boyle G, Mann J, Zeybel M, et al. (2010). Acetate, the key modulator of inflammatory responses in acute alcoholic hepatitis. Hepatology 51: 1988-1997.http://dx.doi.org/10.1002/hep.23572

Marques C, Oliveira CS, Alves S, Chaves SR, et al. (2013). Acetate-induced apoptosis in colorectal carcinoma cells involves lysosomal membrane permeabilization and cathepsin D release. Cell Death Dis. 4: e507-e518. http://dx.doi. org/10.1038/cddis.2013.29

Maslowski KM, Vieira AT, Ng A, Kranich J, et al. (2009). Regulation of inflammatory responses by gut microbiota and chemoattractant receptor GPR43. Nature 461: 1282-1286. http://dx.doi.org/10.1038/nature08530

Oliveira CSF, Pereira H, Alves S, Castro L, et al. (2015). Cathepsin D protects colorectal cancer cells from acetate-induced apoptosis through autophagy-independent degradation of damaged mitochondria. Cell Death Dis. 6: e1788. http:// dx.doi.org/10.1038/cddis.2015.157

Park SY, Cho SJ, Kwon HC, Lee KR, et al. (2005). Caspase-independent cell death by allicin in human epithelial carcinoma cells: involvement of PKA. Cancer Lett. 224: 123-132.http://dx.doi.org/10.1016/j.canlet.2004.10.009

Qi F, Li A, Inagaki Y, Xu H, et al. (2012). Induction of apoptosis by cinobufacini preparation through mitochondria- and Fas-mediated caspase-dependent pathways in human hepatocellular carcinoma cells. Food Chem. Toxicol. 50: 295302.http://dx.doi.org/10.1016/j.fct.2011.10.040

Rikiishi H (2012). Novel insights into the interplay between apoptosis and autophagy. Int. J. Cell Biol. 2012: 317645. http://dx.doi.org/10.1155/2012/317645

Soliman ML and Rosenberger TA (2011). Acetate supplementation increases brain histone acetylation and inhibits histone deacetylase activity and expression. Mol. Cell. Biochem. 352: 173-180. http://dx.doi.org/10.1007/s11010-011-0751-3

Sun J, Bi L, Chi Y, Aoki K, et al. (2005). Effect of sodium acetate on cell proliferation and induction of proinflammatory cytokines: a preliminary evaluation. Food Chem. Toxicol. 43: 1773-1780. http://dx.doi.org/10.1016/j.fct.2005.05.020

Tedelind S, Westberg F, Kjerrulf M and Vidal A (2007). Anti-inflammatory properties of the short-chain fatty acids acetate and propionate: a study with relevance to inflammatory bowel disease. World J. Gastroenterol. 13: 2826-2832.

US Government Printing Office (2011). Title 21 Code of Federal Regulations (CFR) Part 150,141. Ofðce of Federal Register, National Archives and Records Administration, Washington.

Vinolo MAR, Rodrigues HG, Hatanaka E, Sato FT, et al. (2011). Suppressive effect of short-chain fatty acids on production of proinflammatory mediators by neutrophils. J. Nutr. Biochem. 22: 849-855. http://dx.doi.org/10.1016/j. inutbio.2010.07.009

Waldecker M, Kautenburger T, Daumann H, Busch C, et al. (2008). Inhibition of histone-deacetylase activity by shortchain fatty acids and some polyphenol metabolites formed in the colon. J. Nutr. Biochem. 19: 587-593. http://dx.doi. org/10.1016/j.jnutbio.2007.08.002

Willett WC (2000). Diet and cancer. Oncologist 5: 393-404. http://dx.doi.org/10.1634/theoncologist.5-5-393

Genetics and Molecular Research 15 (4): gmr.15048375 